\title{
Vitamin D level is associated with severity of coronary artery atherosclerosis and incidence of acute coronary syndromes in non-diabetic cardiac patients
}

\author{
Ewelina A. Dziedzic ${ }^{1}$, Jakub S. Gąsior ${ }^{2,3}$, Mariusz Pawłowski², Beata Wodejko-Kucharska ${ }^{1}$, \\ Tomasz Saniewski ${ }^{1}$, Anna Marcisz ${ }^{4}$, Marek J. Dąbrowski ${ }^{1,3}$
}

\begin{abstract}
${ }^{1}$ Department of Cardiology, Bielanski Hospital, Warsaw, Poland
${ }^{2}$ Faculty of Health Sciences and Physical Education, Kazimierz Pulaski University of Technology and Humanities, Radom, Poland

${ }^{3}$ Clinical Department of Cardiology of Institute of Cardiology, Bielanski Hospital, Warsaw, Poland

${ }^{4}$ Data Mining Group, Faculty of Automatic Control, Electronic and Computer Science, Silesian University of Technology, Gliwice, Poland
\end{abstract}

Submitted: 3 January 2017

Accepted: 20 March 2017

Arch Med Sci 2019; 15, 2: 359-368

DOI: https://doi.org/10.5114/aoms.2019.83291

Copyright $\odot 2019$ Termedia \& Banach

\begin{abstract}
Introduction: Ischaemic heart disease is the main cause of death in developed countries. There are many modifiable risk factors associated with coronary heart disease (CAD). A growing number of studies point to vitamin $D$ deficiency as a risk factor for heart attacks and the conditions associated with cardiovascular disease. This study aimed to analyse the relationship between the level of 25-hydroxyvitamin $\mathrm{D}(25(\mathrm{OH}) \mathrm{D})$ and the severity of coronary artery atherosclerosis and to study $25(\mathrm{OH}) \mathrm{D}$ levels in non-diabetic patients hospitalised due to acute coronary syndrome and those diagnosed with stable CAD.

Material and methods: Coronary angiography was performed prospectively in 410 successive cardiac patients. The severity of coronary artery atherosclerosis was assessed according to the Coronary Artery Surgery Study Score (CASSS). The plasma 25(OH)D level was assessed with the electrochemiluminescence method.

Results: The $25(\mathrm{OH}) \mathrm{D}$ level proved to be one of the significant determinants of the CASSS $(p<0.05)$. In subjects without significant lesions in the coronary arteries the $25(\mathrm{OH}) \mathrm{D}$ level was significantly higher compared to patients with one- to three-vessel coronary atherosclerosis $(p<0.05)$. A significantly higher 25(OH)D level was noted in patients diagnosed with stable CAD compared to patients hospitalised due to acute coronary syndrome $(p<0.01)$.

Conclusions: Patients with one- to three-vessel atherosclerosis have a significantly lower $25(\mathrm{OH}) \mathrm{D}$ level compared to patients without significant lesions in the coronary arteries. A lower $25(\mathrm{OH}) \mathrm{D}$ level was observed in patients hospitalised due to acute coronary syndrome compared to patients diagnosed with stable CAD.
\end{abstract}

Key words: vitamin D, coronary atherosclerosis, cardiometabolic risk factors.

\section{Introduction}

Despite significant advances in the field of prophylaxis and treatment of cardiac disorders, ischaemic heart disease is still the main cause of

\author{
Corresponding author: \\ Dr. Ewelina A. Dziedzic \\ Department of Cardiology \\ Bielanski Hospital \\ 80 Cegłowska St \\ 01-809 Warsaw, Poland \\ Phone: +48 792207779 \\ E-mail: ewelinadziedzic82@ \\ gmail.com
}


death in developed countries [1-3]. Consequently, much attention is placed on the discovery of new, potentially modifiable cardiovascular risk factors. Vitamin D deficiency is postulated to be one such factor, and it may be associated with an increased risk of circulatory diseases [1-3]. The studies regarding a correlation between vitamin $\mathrm{D}$ and the circulatory system started when a receptor for vitamin D was discovered on the cells of the cardiovascular system and when these cells were shown to synthesise an active metabolite of vitamin $D$ (1,25-dihydroxyvitamin $D)$ in an autocrine manner [4]. Vitamin D, made in the skin from exposure to sunlight or obtained from the diet, is biologically inert and requires its hydroxylation in the liver to 25-hydroxyvitamin D [25(OH)D] [5-8]. The level of $25(\mathrm{OH}) \mathrm{D}$ is measured in clinical settings to assess the adequacy of vitamin D stores [5]. However, $25(\mathrm{OH}) \mathrm{D}$ is not biologically active and requires further hydroxylation in the kidneys to the to the biologically active form, 1,25-dihydroxyvitamin D [1,25(OH)2D], which stimulates intestinal calcium absorption $[5-7,9]$. Lack of vitamin D causes that only about $10-15 \%$ of dietary calcium is absorbed [6]. A low vitamin D level - in comparison to the reference range - can be observed in almost 50\% of the global population [1-3]. Additionally, it has been demonstrated that an insufficient vitamin $D$ level may affect the cardiovascular system via a classic mechanism, namely by promoting changes in the calcium-phosphate metabolism, or via effects on the renin-angiotensin-aldosterone system [10]. Moreover, vitamin D affects numerous cells involved in atherogenesis, such as immune cells, endothelial cells, smooth muscle cells and cardiomyocytes [11-16]. The effects of vitamin D insufficiency were observed at all stages of atherosclerotic plaque formation, destabilisation and rupture [17]. Vitamin D also affects blood extravasation at ruptured atherosclerotic plaque, which is a key element of acute coronary syndrome [17]. Additionally, data from the third National Health and Nutrition Examination Survey (NHANES III) concerning adults from the United States indicated that patients with a low level of $25(\mathrm{OH}) \mathrm{D}$ (less than $21 \mathrm{ng} / \mathrm{ml}$ ) have an increased risk of hypertension, diabetes, obesity, and high triglyceride levels $[18,19]$. The association between low level of vitamin D and mentioned cardiovascular risk factors has been confirmed in other studies [20-23].

However, recently we found that in a sizable heterogeneous Polish population of cardiac patients including those with e.g. hypertension, diabetes, and/or hyperlipidaemia there is no significant correlation between the level of the $25(\mathrm{OH}) \mathrm{D}$ and the stage of coronary atherosclerosis [24]. Subgroup analysis of these data showed that such a relationship may be observed in women. Moreover, men aged $70-80$ years with two- or three-vessel coronary atherosclerosis presented significantly lower values of $25(\mathrm{OH}) \mathrm{D}$ than agematched patients without coronary artery lesions [24]. Additional analysis revealed that the association of 25(OH)D and the stage of coronary atherosclerosis may depend on the diabetic status (data not shown).

Therefore, the main aim of this study was to assess the correlation between 25(OH)D level and the severity of coronary artery atherosclerosis in non-diabetic patients. Moreover, we decided to compare vitamin D levels in patients hospitalised due to acute coronary syndrome and patients diagnosed with stable coronary disease.

\section{Material and methods}

\section{Population}

This study is part of a large project focused on the relationship between level of vitamin D and severity of coronary artery atherosclerosis. The previous analysis concerned 637 patients examined using coronary angiography who we included in the first overall analysis. Detailed characteristics of the study sample are presented elsewhere [24].

Additional analysis aimed at finding determinants of the degree of coronary atherosclerosis showed that one of the independent significant determinant was diabetic status (two groups of patients: without diabetes and with type 2 diabetes). The results obtained for non-diabetic patients assessing the effect of vitamin D on the condition of the coronary arteries and heart attack episodes are presented in this manuscript. In addition to diabetes, other exclusion criteria were: chronic kidney disease (stage III-V), diagnosed cancer, elevated inflammatory markers or fever, medication or supplementation containing vitamin D or calcium. All the enrolled patients were Polish citizens, so it may be presumed that in terms of eating habits and the length of exposure to sunlight they constitute a relatively homogeneous group. The previous analysis was performed in patients who were all treated with statins [24]. Since that time we have continuously examined new patients. In this study most of the patients (99.5\%) were treated with statins (atorvastatin or rosuvastatin) and only $0.5 \%$ ( 2 patients) percent have not received this kind of medication.

\section{Methods}

Coronary angiography was performed in all patients using standard diagnostic catheters through radial or femoral artery access. The degree of coronary atherosclerosis was assessed using the Coronary Artery Surgery Study Score 
(CASSS) [25]. Stenosis larger than $70 \%$ in any of the large epicardial coronary arteries (anterior descending branch - LAD, circumflex branch - LCX, right coronary artery - RCA) was scored as 1 point. Stenosis $\geq 50 \%$ of the left main coronary artery was scored as 2 points and was considered 2-vessel disease. CASSS is calculated as the sum of all scored points. The score may illustrate 1-, 2- or 3-vessel coronary artery disease [25].

The concentration of $25(\mathrm{OH}) \mathrm{D}$ (the major storage form of vitamin D in the body) was measured using "Vitamin D Total" assay (ELECSYS Roche Diagnostics). This competitive electrochemiluminescence method evaluates the levels of both $25(\mathrm{OH}) \mathrm{D}_{2}$ and $25(\mathrm{OH}) \mathrm{D}_{3}$. The sensitivity of this assay was $4.01 \mathrm{ng} / \mathrm{ml}$ and the coefficient of variation (CV) was $18.5 \%$. A recent study showed that the within-run CV of the Elecsys Vitamin D Total assay was $\leq 7 \%$, the within-laboratory CV was $<9.5 \%$, the between-laboratory precision CV was $\leq 10.1 \%$, and functional sensitivity was below $9.8 \mathrm{nmol} / \mathrm{l}$ [26]. A more detailed assay to determine the level of $25(\mathrm{OH}) \mathrm{D}$ - liquid chromatography tandem mass spectrometry (LC-MS/MS), currently considered as the gold standard for 25(OH)D [27] - allows for independent determination of $25(\mathrm{OH}) \mathrm{D}_{3}$ and $25(\mathrm{OH}) \mathrm{D}_{2}$. However, it is expensive and therefore has limited widespread clinical use [28]. It was concluded that the use of less expensive methods to determine the level of both total metabolites of vitamin D is warranted because the biological effects of both metabolites of vitamin D are similar. There exist studies suggesting that Elecsys Vitamin D Total Assay is comparable to LC-MS/MS and appropriate for clinical use [29-31].

Levels of 25(OH)D exceeding $30 \mathrm{ng} / \mathrm{ml}$ are considered optimal, 20-30 ng/ml - mild deficiency, 10-20 ng/ml - moderate deficiency, and a level below $10 \mathrm{ng} / \mathrm{ml}$ - severe deficiency [19].

Hyperlipidaemia was defined when the total cholesterol (TC) was above $200 \mathrm{mg} / \mathrm{dl}$ and/or triglyceride values (TG) were above $150 \mathrm{mg} / \mathrm{dl}$. The levels of TC and TG were measured using the enzymatic method.

Written informed consent was obtained from all the patients participating in the study. The research was approved by the University Bioethical Committee and followed the rules and principles of the Helsinki Declaration.

\section{Statistical analysis}

Normality was evaluated with the Shapiro-Wilk test. Poisson regression analysis was used to assess the relationship between the degree of coronary atherosclerosis (CASSS) and selected variables: level of vitamin $\mathrm{D}(25(\mathrm{OH}) \mathrm{D})$, age, sex, smoking habits, hyperlipidaemia and/or coronary artery disease (CAD) status defined by clinical history of acute coronary syndrome (ACS) compared to stable coronary artery disease (stable CAD). Logistic regression was used to assess the association between 25(OH)D level as well as other covariates such as sex, age, smoking habits and hyperlipidaemia with CAD status. To determine the influence of age, sex, smoking and/or hyperlipidaemia on 25(OH)D level, multivariable regression analysis was carried out. Continuous variables were compared among three or more groups using analysis of variance (ANOVA) or the Kruskal-Wallis test depending on the data distribution. To compare the results of continuous variables between two groups the Mann-Whitney test was used. Pearson's $\chi^{2}$ test was used to determine differences in prevalence between selected groups. Statistical analysis was performed with a significance level of $5 \%(p<0.05)$. The statistical analysis was carried out with Statistica 12 software.

\section{Results}

\section{Participants' characteristics}

The results of the selected group of $410 \mathrm{pa}-$ tients (266 men and 144 women) with mean age $65.4 \pm 10.8$ years were analysed. Acute coronary syndrome was a cause of hospitalization in $33.3 \%$ of the patients. History of heart attack was reported in $23.6 \%$ of the patients. Insignificant changes in the coronary arteries (CASSS 0) were found in $27.6 \%$ of the patients. Single-vessel disease (CASSS 1) was discovered in $29.3 \%$ of the patients, two-vessel (CASSS 2) in 28\%, and triple-vessel (CASSS 3) in $15.1 \%$. The median 25(OH)D concentration in the whole group was $15.0 \mathrm{ng} /$ $\mathrm{ml}(4.0-48.4 \mathrm{ng} / \mathrm{ml})$. In 308 patients 25(OH)D concentration was below $20 \mathrm{ng} / \mathrm{ml}$, while $102 \mathrm{pa}-$ tients had the level of vitamin D above $20 \mathrm{ng} / \mathrm{ml}$. The optimal level of 25(OH)D, i.e. above $30 \mathrm{ng} / \mathrm{ml}$, was observed in $5.4 \%$ of the subjects, whereas severe deficiency $(25(\mathrm{OH}) \mathrm{D}<10 \mathrm{ng} / \mathrm{ml})$ was observed in $21.2 \%$ of the patients. Active smoking was reported by $26.3 \%$ of the patients. Also $18.1 \%$ of patients stated that they were ex-smokers. Hyperlipidaemia was observed in $48.7 \%$ of the patients.

\section{Association of vitamin D level with CASSS}

Detailed results for patients in four subgroups according to CASSS are presented in Table I. There were no significant differences in age or $25(\mathrm{OH}) \mathrm{D}$ level between CASSS subgroups. There was no significant variation in the prevalence of patients in different stages of coronary atherosclerosis among four groups according to the level of vitamin D. The results showed significant variation in the prevalence of patients divided according to 
sex, smoking habits and CAD status among CASSS subgroups.

It can be seen that patients with CASSS 0 presented the highest value of 25(OH)D, nominally higher than patients with CASSS 1-3 (Table I). This was the reason to divide all patients into two groups: CASSS 0 and CASSS 1-3 (Table II). A statistically significant difference in the level of $25(\mathrm{OH}) \mathrm{D}$ between patients without significant coronary lesions (CASSS 0) and those with coronary atherosclerosis (CASSS 1-3) was observed (Figure 1).
More females than males were in the CASSS 0 subgroup and, conversely, more males than females were in CASSS 1 to 3 subgroups. In all CASSS subgroups ( 0 to 3 ) the majority of patients were non-smokers and had stable CAD. There was no significant difference in the prevalence of hyperlipidaemia between two subgroups (CASSS 0 and CASSS 1-3). In the regression analysis, 25(OH)D level, age, sex, smoking and CAD status proved to be a significant determinants of CASSS (Table III).

Table I. Characteristics of the examined group divided according to degree of coronary atherosclerosis (CASSS) into four subgroups

\begin{tabular}{|c|c|c|c|c|c|}
\hline Parameter & CASSS 0 & CASSS 1 & CASSS 2 & CASSS 3 & $P$-value \\
\hline$N(\%)$ & $112(27 \%)$ & $121(30 \%)$ & $115(28 \%)$ & $62(15 \%)$ & - \\
\hline Age [years] ${ }^{\star}$ & $65.2 \pm 10.2$ & $64.1 \pm 11.5$ & $65.5 \pm 10.7$ & $68.7 \pm 9.5$ & 0.06 \\
\hline $\operatorname{Sex}(F / M)$ & $61(15 \%) / 51(12 \%)$ & $36(9 \%) / 85(21 \%)$ & $32(8 \%) / 83(20 \%)$ & $15(4 \%) / 47(12 \%)$ & $<0.001$ \\
\hline $25(\mathrm{OH}) \mathrm{D}[\mathrm{ng} / \mathrm{ml}]^{\star *}$ & $16.8(4.8-42.6)$ & $15.1(4.0-48.4)$ & $13.6(4.4-37.6)$ & $15.2(5.0-42.9)$ & 0.07 \\
\hline \multicolumn{6}{|c|}{ Patients in groups according to the level of $25(\mathrm{OH}) \mathrm{D}$ : } \\
\hline $0-<10$ & $18(4 \%)$ & $27(7 \%)$ & $27(7 \%)$ & $14(3 \%)$ & \multirow[t]{4}{*}{0.47} \\
\hline$\geq 10-<20$ & $56(14 \%)$ & $68(17 \%)$ & $66(16 \%)$ & $32(8 \%)$ & \\
\hline$\geq 20-<30$ & $29(7 \%)$ & $20(5 \%)$ & $18(4 \%)$ & $13(3 \%)$ & \\
\hline$\geq 30$ & $9(2 \%)$ & $6(1 \%)$ & $4(1 \%)$ & $3(1 \%)$ & \\
\hline $\begin{array}{l}\text { Smoking } \\
\text { (No/Yes/Ex-smokers) }\end{array}$ & $\begin{array}{c}79(19 \%) / \\
15(4 \%) / 18(4 \%)\end{array}$ & $\begin{array}{c}63(15 \%) / \\
44(11 \%) / 14(3 \%)\end{array}$ & $\begin{array}{c}54(13 \%) / \\
33(8 \%) / 28(7 \%)\end{array}$ & $\begin{array}{c}32(8 \%) / \\
16(4 \%) / 14(3 \%)\end{array}$ & $<0.001$ \\
\hline $\begin{array}{l}\text { Hyperlipidaemia } \\
\text { (No/Yes) }\end{array}$ & $46(12 \%) / 63(16 \%)$ & $61(15 \%) / 55(14 \%)$ & 49 (12\%)/64 (16\%) & $34(9 \%) / 25(6 \%)$ & 0.13 \\
\hline $\begin{array}{l}\text { CAD status } \\
\text { (stable CAD/ACS) }\end{array}$ & $96(23 \%) / 16(4 \%)$ & $65(16 \%) / 56(14 \%)$ & 74 (18\%)/41 (10\%) & $38(9 \%) / 24(6 \%)$ & $<0.001$ \\
\hline
\end{tabular}

Table II. Comparison of selected parameters between patients without significant coronary lesions (CASSS 0) and those with coronary atherosclerosis (CASSS 1-3)

\begin{tabular}{|c|c|c|c|}
\hline Parameter & CASSS 0 & CASSS $1-3$ & $P$-value \\
\hline$N(\%)$ & $112(27 \%)$ & $298(73 \%)$ & - \\
\hline Age $[$ years]* & $65.2 \pm 10.2$ & $65.6 \pm 10.9$ & 0.77 \\
\hline $\operatorname{Sex}(F / M)$ & $61(15 \%) / 51(12 \%)$ & $83(20 \%) / 215(53 \%)$ & $<0.001$ \\
\hline $25(\mathrm{OH}) \mathrm{D}[\mathrm{ng} / \mathrm{ml}]^{\star *}$ & $16.8(4.8-42.6)$ & $14.3(4.0-48.4)$ & $<0.05$ \\
\hline \multicolumn{4}{|c|}{ Patients in groups according to the level of $25(\mathrm{OH}) \mathrm{D}$ : } \\
\hline $0-<10$ & $18(4 \%)$ & $68(17 \%)$ & 0.06 \\
\hline$\geq 10-<20$ & $56(14 \%)$ & $166(41 \%)$ & \\
\hline$\geq 20-<30$ & $29(7 \%)$ & $51(12 \%)$ & \\
\hline$\geq 30$ & $9(2 \%)$ & $13(3 \%)$ & \\
\hline Smoking (No/Yes/Ex-smokers) & $79(19 \%) / 15(4 \%) / 18(4 \%)$ & $149(36 \%) / 93(23 \%) / 56(14 \%)$ & $<0.001$ \\
\hline Hyperlipidaemia (No/Yes) & $46(12 \%) / 63(16 \%)$ & $144(36 \%) / 144(36 \%)$ & 0.17 \\
\hline CAD status (stable CAD/ACS) & $96(23 \%) / 16(4 \%)$ & $177(43 \%) / 121(30 \%)$ & $<0.001$ \\
\hline
\end{tabular}




\section{Association of vitamin D level with clinical presentation}

Patients with stable CAD presented significantly higher values of $25(\mathrm{OH}) \mathrm{D}$ than patients with ACS (Table IV, Figure 2). There was significant variation in the prevalence of patients in subgroups of CASSS and patients divided according to smoking habits among two groups of CAD status. In the logistic regression analysis, from the determinants age, sex, smoking habits, hyperlipidaemia and 25(OH)D level, the latter was a significant determinant of CAD status (Table $\mathrm{V}$ ).

\section{Association of different factors with vitamin D levels}

From four determinants (age, sex, smoking habits and hyperlipidaemia) only hyperlipidaemia

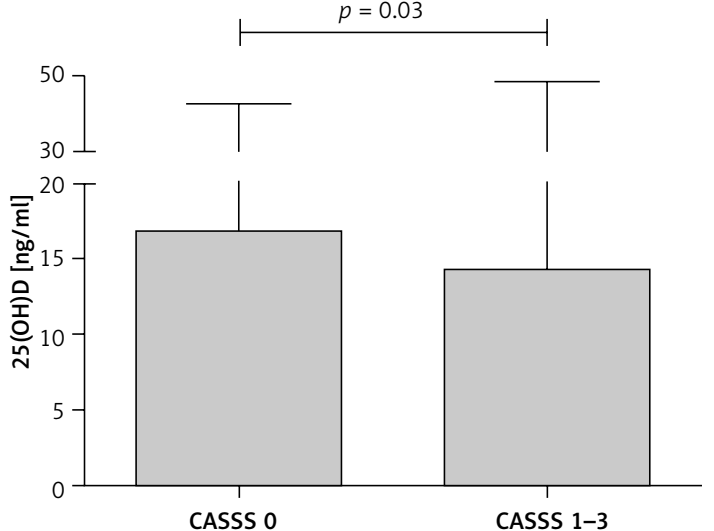

Figure 1. 25(OH)D level in patients without significant coronary lesions (CASSS 0 ) and with coronary atherosclerosis (CASSS 1-3)

Box denotes median and whiskers denote maximum values.

Table III. Results of the Poisson regression analysis considering 25(OH)D level, age, sex, smoking habits, hyperlipidaemia and CAD as determinants of CASSS

\begin{tabular}{|lccc|}
\hline Determinant & OR & $95 \% \mathrm{Cl}$ & $P$-value \\
\hline 25(OH)D & -0.015 & $-0.027--0.002$ & $<0.05$ \\
\hline Age & 0.013 & $0.005-0.022$ & $<0.01$ \\
\hline Sex (F/M) & 0.414 & $0.214-0.614$ & $<0.001$ \\
\hline Smoking (No/Yes/Ex-smokers) & 0.184 & $0.071-0.296$ & $<0.01$ \\
\hline Hyperlipidaemia (No/Yes) & -0.068 & $-0.245-0.109$ & 0.45 \\
\hline CAD status (stable CAD/ACS) & -0.239 & $-0.418--0.060$ & $<0.01$ \\
\hline
\end{tabular}

Table IV. Comparison of selected parameters between patients with stable CAD and ACS

\begin{tabular}{|c|c|c|c|}
\hline Parameter & Stable CAD & ACS & $P$-value \\
\hline$N(\%)$ & $273(67 \%)$ & $137(33 \%)$ & - \\
\hline Age [years] ${ }^{*}$ & $65.5 \pm 10.5$ & $65.3 \pm 11.2$ & 0.84 \\
\hline $\operatorname{Sex}(F / M)$ & $102(25 \%) / 171(42 \%)$ & $42(10 \%) / 95(23 \%)$ & 0.18 \\
\hline $25(\mathrm{OH}) \mathrm{D}[\mathrm{ng} / \mathrm{ml}]^{\star *}$ & $15.6(4.0-48.4)$ & $13.6(4.5-42.9)$ & $<0.01$ \\
\hline \multicolumn{4}{|c|}{ Patients in groups according to the level of $25(\mathrm{OH}) \mathrm{D}$ : } \\
\hline $0-<10$ & $51(12 \%)$ & $35(9 \%)$ & \multirow[t]{4}{*}{0.30} \\
\hline$\geq 10-<20$ & $148(36 \%)$ & $74(18 \%)$ & \\
\hline$\geq 20-<30$ & $58(14 \%)$ & $22(5 \%)$ & \\
\hline$\geq 30$ & $16(4 \%)$ & $6(2 \%)$ & \\
\hline Smoking (No/Yes/Ex-smokers) & $153(37 \%) / 61(15 \%) / 59(14 \%)$ & $75(18 \%) / 47(12 \%) / 15(4 \%)$ & $<0.01$ \\
\hline \multicolumn{4}{|c|}{ Patients in groups according to CASSS: } \\
\hline 0 & $96(23 \%)$ & $16(4 \%)$ & \multirow[t]{4}{*}{$<0.001$} \\
\hline 1 & 65 (16\%) & $56(14 \%)$ & \\
\hline 2 & 74 (18\%) & 41 (10\%) & \\
\hline 3 & 38 (9\%) & $24(6 \%)$ & \\
\hline Hyperlipidaemia (No/Yes) & $123(31 \%) / 142(36 \%)$ & $67(17 \%) / 65$ (16\%) & 0.42 \\
\hline
\end{tabular}




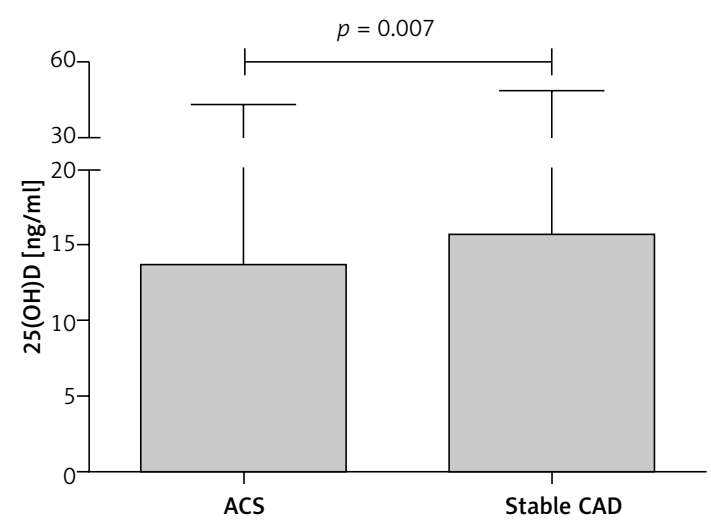

Figure 2. 25(OH)D level in patients hospitalized for an acute coronary syndrome and diagnosed with stable coronary artery disease

ACS - acute coronary syndrome, CAD - coronary artery disease. Box denotes median and whiskers denote maximum values.

was a significant determinant of 25(OH)D level (Table VI). Patients without hyperlipidaemia presented significantly higher values of $25(\mathrm{OH}) \mathrm{D}$ than patients with hyperlipidaemia $(p<0.01)$.

\section{Discussion}

There has been growing evidence that vitamin D deficiency increases the risk of cardiovascular diseases. On the other hand, the optimal concentration of $25(\mathrm{OH}) \mathrm{D}$ exerts a protective action [32-34]. The results of many studies indicate that vitamin $D$ deficiency is commonly observed worldwide $[35,36]$. Based on a review of the literature, namely 195 studies from 44 countries published in 1990-2011, a map of vitamin D supply in the human population worldwide was created and it demonstrated a significantly higher vitamin D level in North America compared to Europe or the Middle East/Africa region [35]. The authors of this work also highlighted that other previous reviews reported differences in vitamin $D$ level between the European countries (a so-called north-south gradient) and higher levels in the Scandinavian countries compared to southern Europe [35].

In one of our studies performed in a group of more than 600 cardiac patients the optimal vitamin D level was observed only in $5 \%$ of patients. The mean value of the vitamin $D$ level in the overall population was $15.9 \mathrm{ng} / \mathrm{ml}$ [24], and the median level of the $25(\mathrm{OH}) \mathrm{D}$ in non-diabetic patients was $15.0 \mathrm{ng} / \mathrm{ml}$. These values are lower than in epidemiological studies that included large numbers of patients, performed e.g. in the United States [18, 37-40]. In the NHANES cohort study only $5 \%$ of participants had values below the cutoff of $11 \mathrm{ng} / \mathrm{ml}$ [37]. In the Atherosclerosis Risk in Communities (ARIC) overall study population the median $25(\mathrm{OH}) \mathrm{D}$ concentration was $23.9 \mathrm{ng} / \mathrm{ml}$ [39]. It should be mentioned that in the ARIC study, in a selected group of participants the value of $25(\mathrm{OH}) \mathrm{D}$ concentration below $17.2 \mathrm{ng} / \mathrm{ml}$ was associated with higher stroke risk [39] and increased risk of incident coronary heart disease [41]. Moreover, the results of the NHANES III study suggested an association of all-cause mortality with $25(\mathrm{OH}) \mathrm{D}$ levels below $17.8 \mathrm{ng} / \mathrm{ml}$ in the general population [42]. Nevertheless, the mean and median values from our studies are in line with results from epidemiological data on vitamin $D$

Table V. Results of the logistic regression analysis considering 25(OH)D level, age, sex, smoking habits and hyperlipidaemia as determinants of CAD status

\begin{tabular}{|lccc|}
\hline Determinant & OR & $95 \% \mathrm{Cl}$ & $P$-value \\
\hline 25(OH)D & 0.034 & $0.002-0.065$ & $<0.05$ \\
\hline Age & 0.002 & $-0.019-0.023$ & 0.87 \\
\hline Sex (F/M) & -0.330 & $-0.795-0.135$ & 0.16 \\
\hline Smoking (No/Yes/Ex-smokers) & 0.165 & $-0.126-0.457$ & 0.27 \\
\hline Hyperlipidaemia (No/Yes) & 0.237 & $-0.198-0.671$ & 0.29 \\
\hline
\end{tabular}

Table VI. Results of multiple regression analysis considering age, sex, smoking habits and hyperlipidaemia as determinants of $25(\mathrm{OH}) \mathrm{D}$

\begin{tabular}{|c|c|c|c|c|c|c|}
\hline & \multicolumn{6}{|c|}{ Parameters of multiple regression analysis } \\
\hline & Determinant & $\beta$ & $P$-value & Multiple $R^{2}$ & F-test & $P$-value \\
\hline \multirow[t]{4}{*}{$25(\mathrm{OH}) \mathrm{D}$} & Age & 0.05 & 0.39 & 0.031 & 3.15 & $<0.01$ \\
\hline & $\operatorname{Sex}(F / M)$ & 0.08 & 0.11 & & & \\
\hline & Smoking (No/Yes/Ex-smokers) & 0.03 & 0.64 & & & \\
\hline & Hyperlipidaemia (No/Yes) & -0.15 & $<0.01$ & & & \\
\hline
\end{tabular}


status in the Polish population $[43,44]$. Płudowski et al. demonstrated massive vitamin D deficiency in Poland $[43,44]$. The authors measured vitamin D level in late winter and early spring in 5775 healthy people from 22 Polish towns. The mean value of $25(\mathrm{OH}) \mathrm{D}$ for the population was 18.0 $\mathrm{ng} / \mathrm{ml}$. In approximately $66 \%$ of participants the 25(OH)D level was below $20 \mathrm{ng} / \mathrm{ml}$, and optimal values (namely above $30 \mathrm{ng} / \mathrm{ml}$ ) were observed only in $9 \%$ of subjects [43]. Similar results were obtained by another Polish team [45]. The study conducted in more than 400 adults living only in the north of Poland demonstrated that in $84 \%$ of subjects the 25(OH)D level was below $20 \mathrm{ng} / \mathrm{ml}$, and the optimal level was noted only in $3 \%$ of respondents [45].

We found previously in the overall study group, i.e. without restriction to only non-diabetic patients, that the mean $25(\mathrm{OH}) \mathrm{D}$ level was significantly lower in female than in male Polish cardiac patients [24]. Moreover, there existed some differences in the association between 25(OH)D and severity of coronary artery atherosclerosis related to the patients' sex and age. All female patients without significant lesions in the coronary arteries presented significantly higher $25(\mathrm{OH}) \mathrm{D}$ values than females with two- and three-vessel disease. On the other hand, only male cardiac patients aged between 70 and 80 years old with two- or three-vessel coronary atherosclerosis presented significantly lower values of $25(\mathrm{OH}) \mathrm{D}$ than age-matched male patients without coronary artery lesions. Such results were not found in younger participants [24]. The present study analysing the results of non-diabetic cardiac patients demonstrated that all participants (independently of sex) without significant lesions in the coronary arteries (CASSS 0) had a significantly higher $25(\mathrm{OH}) \mathrm{D}$ level compared to patients with coronary artery disease (CASSS 1-3). The higher level of vitamin $D$ in patients without significant lesions in the coronary arteries was not affected by participants' age. Firstly, the two groups, i.e., CASSS 0 and CASSS 1-3, did not differ significantly with respect to age. Secondly, age of the patients did not significantly affect the level of vitamin D in all patients. Nevertheless, the proportion of patients presenting with stable CAD compared to ACS decreased from 6.0 in CASSS 0 to 1.5 in CASSS 1-3. Independently, patients with stable CAD presented significantly higher $25(\mathrm{OH}) \mathrm{D}$ values than patients with ACS. Perhaps the higher level of vitamin D in patients with CASSS 0 plays an important role in the stabilization of the existing atherosclerotic plaques. As previously demonstrated, complications of coronary artery disease in the form of myocardial infarction (MI) beyond the significance of coronary artery stenosis also affects the presence of so-called high-risk plaques [46].
The main factors involved in destabilization of the atherosclerotic plaque include a thin layer of connective tissue, large lipid core, activity of inflammatory cells and increased neovascularisation [47]. Calcitriol might prevent destabilization, due to its anti-inflammatory properties and the ability to inhibit transformation of macrophages into foam cells [48] and to suppress the activity of metalloproteinases $[49,50]$. It also negatively influences angiogenesis by inhibition of vascular endothelial growth factor (VEGF) and induction of apoptosis in epithelial cells [51]. Unstable atherosclerotic plaque is more susceptible to disruption. After the rupture, the lipid contents of the plaque are released and the blood coagulation process is initiated [47]. Calcitriol possesses anticoagulant activity, which is exerted through down-regulation of the tissue factor, increased production of thrombomodulin [52] and inhibition of platelet adhesion to endothelium [53].

The results of studies by other authors show a correlation between low 25(OH)D level and severity of coronary artery atherosclerosis. Shor et al. performed a study in a group of 101 successive Israeli patients undergoing elective coronary arteriography. They demonstrated a correlation between low 25(OH)D level and advanced coronary artery disease even after adjustment for such variables as sex, age, body mass index, ethnicity and active tobacco smoking [54]. Based on the study performed in a group with a similar number of patients in India, Syal et al. demonstrated significantly higher incidence of two- and three-vessel disease in patients with vitamin $D$ deficiency compared to patients with a normal $25(\mathrm{OH}) \mathrm{D}$ level (53\% vs. $38 \%$ ). Moreover, the authors demonstrated a significantly higher incidence of diffused coronary artery disease (56\% vs. $34 \%$ ), and a higher number of atherosclerotic lesions in coronary arteries compared with patients with a higher 25(OH)D level [55]. Recently (2015), Verdoia et al. demonstrated a significant correlation between low vitamin D level and the incidence and severity of atherosclerotic lesions [56]. Based on a study conducted in a group of more than 1500 subjects a higher incidence of atherosclerosis in the right and left coronary artery ( $p=0.03$ ) was demonstrated in patients with vitamin $D$ deficiency compared to subjects with a normal level of this vitamin [56]. However, the results of these studies cannot be directly compared to the outcomes obtained in a group of Polish patients as the place of residence of participants varied and therefore the effects of sunlight on the dermal synthesis of vitamin D were different. Moreover, nutritional behaviour was also different. It has to be emphasised that our results regard only Polish cardiac patients. Moreover, contrary to other studies, the 
examined group included only non-diabetic patients and, as it is known, type 2 diabetes largely modifies the course of coronary artery disease. Analysing the results of our study and the results of other studies documenting the effects of vitamin D on individual stages of atherogenesis, it can be suggested that vitamin $D$ deficiency should be considered a coronary artery disease risk factor.

Apart from the effects on arterial atherosclerosis, it was demonstrated that vitamin $D$ deficiency was associated with an increased risk of unfavourable cardiovascular incidents, including acute coronary syndrome. In our study we observed a significantly lower $25(\mathrm{OH}) \mathrm{D}$ level in patients hospitalised due to $\mathrm{MI}$, despite the fact that, contrary to other studies, our study included only non-diabetic patients. Based on the studies published so far, it is known that in the group of diabetic patients the total mortality rate is doubled and the cardiovascular mortality rate is tripled compared to non-diabetic patients [57]. In relation to the above, we decided to study the effects of vitamin $\mathrm{D}$ on the risk of $\mathrm{MI}$ in diabetic patients in a separate study.

Our results indicating an association between low vitamin D levels and incidents of $\mathrm{MI}$ are confirmed by other studies performed so far. The large Framingham Offspring Study performed in a group of subjects without a history of circulatory diseases demonstrated that the risk of unfavourable cardiovascular incidents, including inter alia $\mathrm{MI}$, was more than 1.5 times higher in patients with 25(OH)D levels below $15 \mathrm{ng} / \mathrm{ml}$ compared to study subjects with the levels of this vitamin above $15 \mathrm{ng} / \mathrm{ml}$ [58]. In a prospective study conducted in patients hospitalised due to ST-segment elevation MI Khalili et al. observed the 25(OH)D level below $14 \mathrm{ng} / \mathrm{ml}$ in $73 \%$ of patients. Additionally, they observed a statistically significant inverse correlation between $25(\mathrm{OH}) \mathrm{D}$ level and plasma level of metalloproteinase- 9 and a higher mortality rate in patients with a lower vitamin D level [59]. The study assessing the effects of vitamin D level on major adverse cardiac events (MACE) defined as death, hospitalisation due to heart failure and/or MI provided interesting findings [60]. It was concluded that the 25(OH)D level was an independent risk factor for MACE ( $p=0.001)$, especially non-fatal MACE. Moreover, the 25(OH)D level above $7.3 \mathrm{ng} /$ $\mathrm{ml}$ reduced the risk of non-fatal MACE by $40 \%$ in patients with acute coronary syndrome [60]. Despite the large body of data confirming our results and the hypothesis that there is a correlation between low vitamin D level and an increased risk of unfavourable cardiovascular incidents, there are also studies that do not confirm this relation. No statistically significant correlation between vitamin D level and the risk of cardiovascular death was observed in the study of the Finnish population [61].

Summing up, the results of our paper and of the majority of other publications indicate that the vitamin D level is, to some degree, associated with the severity of coronary artery disease. Undoubtedly, it is necessary to perform further well-designed studies in a larger group of Polish patients in order to confirm the role of vitamin $D$ in the primary and secondary prevention of ischaemic heart disease.

There are several limitations to our study that have to be considered. The experiment was performed among specific group of participants. Our study group included only patients from central Poland, mainly living in urban areas. The majority of patients were treated with statins. The study did not account for the drug dose or the duration of the treatment, and treatment with statins is well known to affect the vitamin D level [62, 63]. Hence, the inferences cannot be extended to different populations. The study was observational and cross-sectional. Thus, it cannot prove causation, but only demonstrate statistical associations.

In conclusion, vitamin D deficiency was found in nearly $95 \%$ of Polish cardiac patients without diabetes undergoing coronary angiography. We demonstrated that in patients without significant lesions in the coronary arteries the $25(\mathrm{OH}) \mathrm{D}$ level was significantly higher compared to patients with advanced coronary artery disease. Moreover, a significantly lower $25(\mathrm{OH}) \mathrm{D}$ level was observed in patients hospitalised due to acute coronary syndrome compared to patients diagnosed with stable coronary disease.

Although the recommendations of scientific societies do not include vitamin D supplementation as a method of prevention and inhibition of progression of coronary artery disease, further studies are required to assess the potential beneficial effects of such treatment in patients with such diseases.

\section{Acknowledgments}

We thank the independent reviewers for their useful comments.

\section{Conflict of interest}

The authors declare no conflict of interest.

\section{References}

1. Zittermann A, Schleithoff SS, Koerfer R. Putting cardiovascular disease and vitamin $D$ insufficiency into perspective. Br J Nutr 2005; 94: 483-92.

2. Holick MF. Vitamin D deficiency. N Engl J Med 2007; 357: 266-81. 
3. Holick MF, Binkley NC, Bischoff-Ferrari HA, et al. Evaluation, treatment, and prevention of vitamin D deficiency: an Endocrine Society clinical practice guideline. J Clin Endocrinol Metab 2011; 96: 1911-30.

4. Giovannucci E. Expanding roles of vitamin D. J Clin Endocrinol 2009; 94: 418-20.

5. Swanson CM, Nielson CM, Shrestha S, et al. Higher $25(\mathrm{OH}) \mathrm{D} 2$ is associated with lower 25(OH)D3 and 1,25(OH)2D3. J Clin Endocrinol Metab 2014; 99: 2736-44.

6. Nair R, Maseeh A. Vitamin D: the "sunshine" vitamin. J Pharmacol Pharmacother 2012; 3: 118-26.

7. Bikle DD. Vitamin D metabolism, mechanism of action, and clinical applications. Chem Biol 2014; 21: 319-29.

8. Dziedzic E, Dabrowski MJ. Is vitamin D a new therapeutic option in coronary artery disease? Overview data Cardiol Pharmacol 2015; S1: 003.

9. Krela-Kaźmierczak I, Szymczak A, Łykowska-Szuber L, et al. The importance of vitamin $D$ in the pathology of bone metabolism in inflammatory bowel diseases. Arch Med Sci 2015; 11: 1028-32.

10. Li YC, Kong J, Wei M, Chen ZF, Liu SQ, Cao LP. 1,25-Dihydroxyvitamin $\mathrm{D}(3)$ is a negative endocrine regulator of the emode-angiotensin system. J Clin Invest 2002, 110: 229-38.

11. Brewer LC, Michos ED, Reis JP. Vitamin D in atherosclerosis, vascular disease, and endothelial function. Curr Drug Targets 2011; 12: 54-60.

12. Pilz S, Tomaschitz A, Drechsler C, Dekker JM, März W. Vitamin D deficiency and myocardial diseases. Mol Nutr Food Res 2010; 54: 1103-13.

13. Chen S, Glenn DJ, Ni W, et al. Expression of the vita$\min \mathrm{D}$ receptor is increased in the hypertrophic heart. Hypertension 2008; 52: 1106-12.

14. Somjen D, Weisman Y, Kohen F, et al. 25-hydroxyvitamin D3-1alpha-hydroxylase is expressed in human vascular smooth muscle cells and is upregulated by parathyroid hormone and estrogenic compounds. Circu lation 2005; 111: 1666-71.

15. Xiang W, Kong J, Chen S, et al. Cardiac hypertrophy in vitamin $\mathrm{D}$ receptor knockout mice: role of the systemic and cardiac emode-angiotensin systems. Am J Physio Endocrinol Metab 2005; 288: 125-32.

16. Zhou C, Lu F, Cao K, Xu D, Goltzman D, Miao D. Calcium-independent and 1,25(OH2)D3-dependent regulation of the emode-angiotensin system in 1a-hydroxylase knockout mice. Kidney Int 2008; 74: 170-9.

17. Kassi E, Adamopoulos C, Basdra EK, Papavassiliou AG. Role of vitamin D in atherosclerosis. Circulation 2013; 128: 2517-31.

18. Martins D, Wolf M, Pan D, et al. Prevalence of cardiovascular risk factors and the serum levels of 25-hydroxyvitamin D in the United States: data from the Third National Health and Nutrition Examination Survey. Arch Intern Med 2007; 167: 1159-65.

19. Thacher TD, Clarke BL. Vitamin D insufficiency. Mayo Clin Proc 2011; 86: 50-60.

20. Ferrario CM, Strawn WB. Role of the renin angiotensin-aldosterone system and proinflammatory mediators in cardiovascular disease. Am J Cardiol 2006; 98: 121-8.

21. Gagnon C, Lu ZX, Magliano DJ, et al. Low serum 25-hydroxyvitamin $D$ is associated with increased risk of the development of the metabolic syndrome at five years: results from a national, population-based prospective study. J Clin Endocrinol Metab 2012; 97: 1953-61.

22. Pittas AG, Lau J, Hu FB, Dawson-Hughes B. The role of vitamin $D$ and calcium in type 2 diabetes. A systematic review and metaanalysis. J Clin Endocrinol Metab 2007; 92: 2017-29.
23. Lamendola CA, Ariel D, Feldman D, Reaven GM. Relations between obesity, insulin resistance, and 25-hydroxyvitamin D. Am J Clin Nutr 2012; 95: 1055-105.

24. Dziedzic EA, Przychodzeń S, Dąbrowski M. The effects of vitamin D on severity of coronary artery atherosclerosis and lipid profile of cardiac patients. Arch Med Sci 2016; 12: 1199-206.

25. Ringqvist I, Fisher LD, Mock M, et al. Prognostic value of angiographic indices of coronary artery disease from the Coronary Artery Surgery Study (CASS). J Clin Invest 1983; 71: 1854-66.

26. Wielders JP, Carter GF, Eberl H, Morris G, Roth HJ, Vogl C. Automated competitive protein-binding assay for total $25-\mathrm{OH}$ vitamin $\mathrm{D}$, multicenter evaluation and practical performance. J Clin Lab Anal 2015; 29: 451-61.

27. Ashwell M, Stone EM, Stolte $\mathrm{H}$, et al. UK Food Standards Agency Workshop Report: an investigation of the relative contributions of diet and sunlight to vitamin D status. Br J Nutr 2010; 104: 603-11.

28. Black LJ, Anderson D, Clarke MW, Ponsonby AL, Lucas RM; Ausimmune Investigator Group. Analytical bias in the measurement of serum 25-hydroxyvitamin D concentrations impairs assessment of vitamin D status in clinical and research settings. PLoS One 2015; 10: e0135478.

29. Shin SY, Kwon MJ, Song J, Park H, Woo HY. Measurement of serum total vitamin D $(25-\mathrm{OH})$ using automated immunoassay in comparison [corrected] with liquid chromatography tandem-mass spectrometry. J Clin Lab Anal 2013; 27: 284-9.

30. Knudsen CS, Nexo E, Højskov CS, Heickendorff L. Analytical validation of the Roche $25-\mathrm{OH}$ vitamin D total assay. Clin Chem Lab Med 2012; 50: 1965-8.

31. Abdel-Wareth L, Haq A, Turner A, et al. Total vitamin D assay comparison of the Roche Diagnostics "Vitamin D total" electrochemiluminescence protein binding assay with the Chromsystems HPLC method in a population with both D2 and D3 forms of vitamin D. Nutrients 2013; 5: 971-80.

32. Spiro A, Buttriss JL. Vitamin D: an overview of vitamin D status and intake in Europe. Nutr Bull 2014; 39: 322-50.

33. Lee JH, Gadi R, Spertus JA, Tang F, O’Keefe JH. Prevalence of vitamin $D$ deficiency in patients with acute myocardial infarction. Am J Cardiol 2011; 107: 1636-8.

34. Pludowski P, Holick MF, Pilz S, et al. Vitamin D effects on musculoskeletal health, immunity, autoimmunity, cardiovascular disease, cancer, fertility, pregnancy, dementia and mortality - a review of recent evidence. Autoimmun Rev 2013; 12: 976-89.

35. Hilger J, Friedel A, Herr R, et al. A systematic review of vitamin D status in populations worldwide. $\mathrm{Br} J$ Nutr 2014; 111: 23-45.

36. Pludowski P, Grant WB, Bhattoa HP, et al. Vitamin D status in Central Europe. Int J Endocrinol 2014; 2014: 589587.

37. Yetley EA. Assessing the vitamin D status of the US population. Am J Clin Nutr 2008; 88: 558S-64S.

38. Zadshir A, Tareen N, Pan D, Norris K, Martins D. The prevalence of hypovitaminosis D among US adults: data from the NHANES III. Ethn Dis 2005; 15 (4 Suppl 5): S5-97-101.

39. Schneider AL, Lutsey PL, Selvin E et al. Vitamin D, vitamin $D$ binding protein gene polymorphisms, race and risk of incident stroke: the Atherosclerosis Risk in Communities (ARIC) study. Eur J Neurol 2015; 22: 1220-7.

40. Mazidi M, Michos ED, Banach M. The association of telomere length and serum 25-hydroxyvitamin D levels in 
US adults: the National Health and Nutrition Examination Survey. Arch Med Sci 2017; 13: 61-5.

41. Michos ED, Misialek JR, Selvin E, et al. 25-hydroxyvitamin $D$ levels, vitamin $D$ binding protein gene polymorphisms and incident coronary heart disease among whites and blacks: the ARIC study. Atherosclerosis 2015; 241: 12-7.

42. Melamed ML, Michos ED, Post W, Astor B. 25-hydroxyvitamin D levels and the risk of mortality in the general population. Arch Intern Med 2008; 168: 1629-37.

43. Płudowski P, Ducki C, Konstantynowicz J, Jaworski M. Vitamin D status in Poland. Pol Arch Med Wewn 2016; 126: 530-9.

44. Płudowski P, Konstantynowicz J, Jaworski M, et al. Assessment of supply of vitamin $D$ in the adult population in Poland. Standardy Med Pediatria 2014; 4: 609-17.

45. Kmieć P, Żmijewski M, Waszak P, Sworczak K, Lizakowska-Kmieć $M$. Vitamin $D$ deficiency during winter months among an adult, predominantly urban, population in Northern Poland. Endokrynol Pol 2014; 65: 105-13.

46. Puchner SB, Liu T, Mayrhofer T, et al. High-risk plaque detected on coronary CT angiography predicts acute coronary syndromes independent of significant stenosis in acute chest pain: results from the ROMICAT-II trial. J Am Coll Cardiol 2015; 64: 684-92.

47. Beręsewicz A. Pathophysiology of atherosclerosis and cardiovascular disease. Poland 2011.

48. Oh J, Weng S, Felton SK, et al. 1,25(OH)2 vitamin D inhibits foam cell formation and suppresses macrophage cholesterol uptake in patients with type 2 diabetes mellitus. Circulation 2009; 120: 687-98.

49. Timms PM, Mannan N, Hitman GA, et al. Circulating MMP9, vitamin D and variation in the TIMP-1 response with VDR genotype: mechanisms for inflammatory damage in chronic disorders. QJM 2002; 95: 787-96.

50. Fic P, Zakrocka I, Kurzepa J, Stepulak A. [Matrix metalloproteinases and atherosclerosis]. Postepy Hig Med Dosw 2011; 65: 16-27.

51. Osborne JE, Hutchinson PE. Vitamin D and systemic cancer: is this relevant to malignant melanoma? $\mathrm{Br} J$ Dermatol 2002; 147: 197-213.

52. Ohsawa M, Koyama T, Yamamoto K, Hirosawa S, Kamei S, Kamiyama R. 1alpha, 25-dihydroxyvitamin D(3) and its potent synthetic analogs downregulate tissue factor and upregulate thrombomodulin expression in monocytic cells, counteracting the effects of tumor necrosis factor and oxidized LDL. Circulation 2000; 102: 2867-72.

53. Stach K, Kalsch Al, Nguyen XD, et al. 1alpha, 25-dihydroxyvitamin D3 attenuates platelet activation and the expression of vcam-1 and mt1-mmp in human endothelial cells. Cardiology 2011; 118: 107-15.

54. Shor R, Tirosh A, Shemesh L, et al. 25 hydroxyvitamin D levels in patients undergoing coronary artery catheterization. Eur J Intern Med 2012; 23: 470-3.

55. Syal SK, Kapoor A, Bhatia E, et al. Vitamin D deficiency, coronary artery disease, and endothelial dysfunction: observations from a coronary angiographic study in Indian patients. J Invasive Cardiol 2012; 24: 385-9.

56. Verdoia M, Schaffer A, Sartori C, et al. Vitamin D deficiency is independently associated with the extent of coronary artery disease. Eur J Clin Invest 2014; 44: 634-42.

57. Taylor KS, Heneghan CJ, Farmer AJ, et al. All-cause and cardiovascular mortality in middle-aged people with type 2 diabetes compared with people without diabe- tes in a large U.K. primary care database. Diabetes Care 2013; 36: 2366-71.

58. Wang TJ, Pencina MJ, Booth SL, et al. Vitamin D deficiency and risk of cardiovascular disease. Circulation 2008, 117: 503-11.

59. Khalili H, Talasaz AH, Salarifar M. Serum vitamin D concentration status and its correlation with early biomarkers of emodelling following acute myocardial infarction. Clin Res Cardiol 2012; 101: 321-7.

60. Ng LL, Sandhu JK, Squire IB, Davies JE, Jones DJ. Vitamin $\mathrm{D}$ and prognosis in acute myocardial infarction. Int J Cardiol 2013; 168: 2341-6.

61. Kilkkinen A, Knekt P, Aro A, et al. Vitamin D status and the risk of cardiovascular disease death. Am J Epidemiol 2009; 170: 1032-9.

62. Mazidi M, Rezaie P, Vatanparast $H$, Kengne AP. Effect of statins on serum vitamin $D$ concentrations: a systematic review and meta-analysis. Eur J Clin Invest 2017; 47: 93-101.

63. Sahebkar A, Reiner Ž, Simental-Mendía LE, Ferretti G, Corte CD, Nobili V. Impact of statin therapy on plasma vitamin D levels: a systematic review and meta-analysis. Curr Pharm Des 2017; 23: 861-9. 